IZA DP No. 5391

Hierarchical Organization and Inequality in an

Economy with an Implicit Market for Productive Time

Bertrand Candelon

Arnaud Dupuy

December 2010

Forschungsinstitut

zur Zukunft der Arbeit

Institute for the Study

of Labor 


\title{
Hierarchical Organization and Inequality in an Economy with an Implicit Market for Productive Time
}

\author{
Bertrand Candelon \\ Maastricht University \\ Arnaud Dupuy \\ ROA, Maastricht University \\ and IZA
}

\section{Discussion Paper No. 5391 \\ December 2010}

\author{
IZA \\ P.O. Box 7240 \\ 53072 Bonn \\ Germany \\ Phone: +49-228-3894-0 \\ Fax: +49-228-3894-180 \\ E-mail: iza@iza.org
}

\begin{abstract}
Any opinions expressed here are those of the author(s) and not those of IZA. Research published in this series may include views on policy, but the institute itself takes no institutional policy positions.

The Institute for the Study of Labor (IZA) in Bonn is a local and virtual international research center and a place of communication between science, politics and business. IZA is an independent nonprofit organization supported by Deutsche Post Foundation. The center is associated with the University of Bonn and offers a stimulating research environment through its international network, workshops and conferences, data service, project support, research visits and doctoral program. IZA engages in (i) original and internationally competitive research in all fields of labor economics, (ii) development of policy concepts, and (iii) dissemination of research results and concepts to the interested public.
\end{abstract}

IZA Discussion Papers often represent preliminary work and are circulated to encourage discussion. Citation of such a paper should account for its provisional character. A revised version may be available directly from the author. 
IZA Discussion Paper No. 5391

December 2010

\section{ABSTRACT}

\section{Hierarchical Organization and Inequality in an Economy with an Implicit Market for Productive Time*}

This paper proposes an equilibrium theory of the organization of work in an economy with an implicit market for productive time. In this economy, agents have limited productive time and can choose to produce in autarky, buy productive time from helpers to increase own production or, sell their productive time to a leader and thereby give up own production. This implicit market gives rise to the formation of teams, organized in hierarchies with one leader at the top and helpers below. We show that relative to autarky, hierarchical organization leads to higher within and between team payoffs/productivity inequality. We investigate this link empirically in the context of road cycling. We show that the rise in performance inequality in the peloton since the 1970 s is merely due to a rise in within team performance inequality and consistent with a change in the hierarchical organization of teams and an increase in the helping intensity within team.

JEL Classification: D2, D3, L22

Keywords: hierarchical organization, productive time, helping time, inequality, professional cycling

Corresponding author:

Arnaud Dupuy

ROA and Department of Economics

Maastricht University

P.O. Box 616

NL-6200 MD Maastricht

The Netherlands

E-mail: a.dupuy@maastrichtuniversity.nl

\footnotetext{
* We thank Yin-Wong Cheung, Michael Sattinger and Jesper van Thor for their valuable comments and Sander Dijksman for his assistance in gathering and cleaning the raw data.
} 


\section{Introduction}

This paper studies an economy with an implicit market for productive time. The scarce resource in this market is the time each agent can dedicate to production. Agents can dedicate their productive time to their own production (autarky), buy (part of the) productive time from helpers and herewith increase their own production, or sell (part of) their productive time to a leader, hence giving up own production. Since helping time of better helpers is more efficient, the hedonic equilibrium price for productive time compensates i) forgone own production and ii) helping ability. This implicit market for productive time gives rise to teams' formation. These teams have a hierarchical organization with a leader at the top producing output with the help of helpers below.

There are many examples of goods and services produced with teams organized that way. We may think for instance of a lawsuit. The defence of a case is performed by a leading lawyer who receives full credit for the outcome of the trial. The leading lawyer however might receive help from other lawyers at his/her firm to prepare a trial. The opportunity cost of spending productive time helping the leading lawyer requires a compensating wage. Similarly, such an organization is encountered in architect offices whose 
aim is to obtaining large projects by assigning a team of architects to a leading architect. The leading architect receives full credit for the success of the project while the time devoted by helping architects to the project generates an opportunity cost that requires a compensating wage. Yet another example is Haute Couture. A Haute Couture collection is generally fashioned by a group of stylists assisting a couturier. The couturier takes full credit for the success of the collection while the time devoted by a stylist in assisting the couturier is associated with the opportunity cost of not working at her own collection. This opportunity cost requires a compensation. Yet, we can also think of the music industry and the formation of bands or even consider certain sports such as professional road cycling and the structure of teams.

The existence of an implicit market for productive time raises many interesting questions about the structure of such an economy. For instance, who becomes a leader and who becomes a helper? Are leaders better than helpers? Are better helpers assigned to more able leaders? How does the distribution of payoffs look like? Is there more inequality in payoffs with hierarchical organization than with autarky?

We develop a theoretical model in which the distribution of roles (leaders, helpers and self-production), the assignment of leaders to helpers, and 
the distribution of payoffs (the hedonic price for productive time) are endogenously determined. The primitives of the model are the distribution of ability, the shape of the surplus function of teams and the efficiency of helping time. We show that under mild conditions, an equilibrium in this economy exists, is optimal and assignment is so that i) within teams the better rider becomes the leader, ii) better helpers are matched with better leaders and iii) some form of stratification arises: more able agents either become leaders or helpers and less able agents either become a helper or ride individually. The model can be used to study the link between hierarchical organization and productivity and/or payoffs inequality. For instance, we show that relative to autarky, hierarchical organization leads to greater payoffs/performance inequality.

The model developed in this paper is most closely related to the onesided assignment ${ }^{1}$ models in a knowledge economy studied by Garicano and his various coauthors. In particular, Garicano and Rossi-Hansberg (2006), present an economy in which hierarchical organization arises as an efficient way of sharing knowledge. The scarce resource in this model is knowledge.

\footnotetext{
${ }^{1}$ This contrasts with two-sided assignment models studied in Tinbergen (1956), Becker (1973), Rosen (1974) and Sattinger (1993) among others where agents on one side of the market (workers, women, buyers) meet agents on the other side of the market (firms, men, sellers).
} 
Agents can buy knowledge either directly by learning, which is costly, or indirectly by "hiring" more knowledgeable agents to solve problems they cannot solve themselves. In these hierarchical organizations, output is merely produced by workers helped by more knowledgeable agents called managers. This contrasts sharply with the economy depicted in this paper where a team's output is primarily generated by the leader, the most able agent of the team, with the help of helpers that forgo own production. The differences between the two models is also salient in the stratification that arises in equilibrium. In Garicano and Rossi-Hansberg (2006), a strict stratification arises with production workers at the bottom of the distribution of ability, self-employed in the middle and managers (helpers) at the top. Our model allows for a more general form of stratification in equilibrium: while leaders are more able than self-employed, some helpers may be more able than some leaders (of different helpers). Similarly, self-employed agents could be less or more able than helpers depending on the primitives of the model.

We investigate empirically the question of whether performance inequality is larger in an economy with hierarchical organization or in autarky by considering the evolution of performance in road cycling. Especially the organization of teams for the Tour de France strikes us as the relevant framework 
to investigate such a relationship for at least four reasons. First, considering sport allows us to have an observed measure of the productivity and hence of its inequality. In cycling, productivity corresponds to the velocity (average speed) of a rider. The higher the velocity, the higher the probability to win the race and to earn large prizes for the team. Second, even though road cycling essentially sanctions an individual performance, the peloton (group of riders) is organized into teams which allows for strategic behavior within teams. Within team organization is hierarchical and is built around a leader ${ }^{2}$ who is exposed in the media and helpers. Third, teams are of fixed size (9 riders) allowing us to abstract from the extensive margin and focus on helping time. Finally, as we will argue below, incentives to organize teams in the Tour de France have tremendously increased over time (since the end of the 60 's and the transition from national teams to trade teams). The Tour de France provides us an exceptional example of a change in market structure from low to high hierarchical organization, herewith allowing us to evaluate the specific role of increased hierarchical organization, alongside internationalization and technological progress, in the evolution of performance inequality.

\footnotetext{
${ }^{2}$ The most famous ones are at the moment Lance Armstrong, Alberto Contador and Andy Schlek.
} 
Anticipating on our results we show that the bulk of the overall increase in velocity inequality is due to the rise in within team inequality. This result points toward specialization, that is increased help intensity of helpers to their leaders, as the explanation for the rise in velocity inequality among the peloton.

The remainder of the paper is organized as follows. Section 2 proposes a theoretical model that introduces hierarchical organization arising from the existence of an implicit market for productive time. Section 3 studies the example of professional road cycling and in particular the Tour de France. Section 4 concludes.

\section{$2 \quad$ Theoretical model}

\section{$2.1 \quad$ Set up}

We present the model using the analogy to the Tour de France but one could also replace riders by "agents" throughout this section. Let riders be endowed with one unit of time and with ability $z, z \in Z$ where $Z=[\underline{z} ; \bar{z}]$ with $0<\underline{z} \leq \bar{z}<<\infty,{ }^{3}$ drawn from a distribution with $\mathrm{PDF} d(z)$ and $\mathrm{CDF}$

\footnotetext{
${ }^{3}$ We could work with unbounded support for $z$ without changing much of the model but this would require to write down boundary conditions for the functions $f$ and $v$ in our
} 
$D(z)$. We assume that ability is unidimensional and measured in terms of velocity (kilometers per hour) that is, $z$ is the total distance of the Tour divided by the time it would take rider $z$ to cover this distance when riding individually. The mass of riders is assumed to be 1 and $D$ is continuous with respect to Lebesgue measure.

In this economy, riders decide either to ride individually or to coordinate their efforts within teams. The number of riders in a team is fixed exogenously by rules and for the sake of simplicity we assume it is equal to $2 .{ }^{4}$ Within each team, one rider becomes the helper of the other. The two riders must decide who becomes the leader and who becomes the helper. The distribution of roles within teams is endogenous to the model. Conditions under which the most able rider becomes the leader are given below in Proposition 3.

In case riders coordinate their efforts, the helper will devote $s \in[0,1]$ unit of time to his leader. Let $p_{h}\left(z_{h}, s\right)=z_{h}-s a z_{h}$ be the velocity of a helper of ability $z_{h}$ when providing helping time $s$ to his leader. The decrease in the

standing assumptions below.

${ }^{4}$ This assumption restricts the extensive margin compared to Garicano and Hubbard (2006) who study leverage in a knowledge economy. However, this does not seem to be restrictive in our case since the number of riders in each team participating in the Tour is fixed to 9 by rules. 
helper's velocity resulting from one additional unit of time spent helping his leader is proportional to his own ability and equal to $a z_{h} \cdot{ }^{5}$ Similarly, let the velocity of a leader with ability $z_{l}$, helped by a helper of ability $z_{h}$ providing helping time $s$ be $p_{l}\left(z_{l}, s\right)=z_{l}+f\left(z_{h}\right) s$ with $\left(z_{l}, z_{h}\right) \in Z^{2}$, where $f\left(z_{h}\right)$ is a twice differentiable continuous function. The function $f\left(z_{h}\right)$ indicates the increase in the velocity of a leader per unit of helping time provided by a helper of ability $z_{h}$. If $s=0$, even though riders are in the same team, both riders bike individually and their respective velocity is simply $p_{l}\left(z_{l}, 0\right)=z_{l}$ and $p_{h}\left(z_{h}, 0\right)=z_{h}$.

Throughout this paper we maintain the following assumptions about the efficiency of helping time.

\section{Condition 1 Standing Assumptions I (SA I, hereafter)}

1. Helping time is strictly efficient for the leader's velocity, $f(y)>0$ for all $y \in Z$ but strictly costly for the helper's velocity, $1>a>0,{ }^{6}$

\footnotetext{
${ }^{5}$ Note that all that matters in this economy is the relative shape of the loss of helpers' velocity to the gain in leaders' velocity. Assuming a linear shape for the drop in helpers' velocity, i.e. $a z$, is without loss of generality since the properties of the gain in leaders' velocity, i.e. the function $f()$ below are defined relative to $a$.

${ }^{6}$ For $a=1, p_{h}\left(z_{h}, 1\right)=0$. This is unrealistic since during the Tour, riders that do not finish within a certain interval of time after the stage winner are disqualified, i.e. $p_{i}\left(z_{i}, s\right)>p_{\min }$ where $p_{\min }$ is the velocity below which riders are disqualified. This rule is either a constraint on $a$ or a constraint on the helping time riders can provide. In the remaining of the paper, we assume for simplicity that $a$ is low enough, $a<1$, so that $p_{h}\left(z_{h}, 1\right)$ is always large enough for the helper not to be disqualified.
} 
2. The marginal efficiency of helping time for leaders is lower than the marginal cost for helpers, $\frac{f(x)-f(y)}{x-y} \leq a$ for all $(x, y) \in Z^{2}$ with $x>y .^{7}$

3. Better riders are also better helpers, $f^{\prime}(y)>0$ for all $y \in Z$.

Note that intuitively, $f(y)-f(x)-a(y-x)$ is the net gain of velocity in team $\langle x, y\rangle$ obtained if rider $x$ is re-assigned from being the helper to being the leader. SA I.2 therefore stipulates that the net gain is positive if $x$ is the better rider.

Let $v(p)$ be a continuous and twice differentiable function mapping rider's velocity $p$ into money prizes. The function $v$ could change over time to capture for instance a convexification of money prizes; the winner takes it all.

Throughout this paper we maintain the following assumptions about the reward function.

Condition 2 Standing Assumptions II (SA II, hereafter))

1. $v(0)=0$,

2. Rewards $v($.$) are strictly increasing in velocity v^{\prime}(z)>0$,

\footnotetext{
${ }^{7}$ Note that writing $x=y+h$ the constraint becomes $\frac{f(y+h)-f(y)}{h} \leq a$. This must hold for all $h>0$ and all $y \in Z$. Hence, by definition, we have $\lim _{h \rightarrow 0} \frac{f(y+h)-f(y)}{h}=f^{\prime}(y) \leq a$ for all $y \in Z$.
} 
3. Rewards $v($.$) are convex in velocity, i.e. v^{\prime \prime}(z) \geq 0$ for all $z \in Z$,

4. $0<v^{\prime}(z)<<\infty$ for all $0<z<<\infty$.

Note that the assumption of convexity of the reward function is more than supported by empirical data on the distribution of prizes by rank in the final classification, see Figure 6.

Let $Y$ the surplus of a team be given by the sum of all prizes won by its riders. Formally, let $Y\left(z_{l}, z_{h}, s\right)=v\left(z_{l}+f\left(z_{h}\right) s\right)+v\left(z_{h}(1-s)\right)$. Let $w_{h}\left(z_{h}, s\right)$ be the payoffs of a helper $z_{h}$ providing helping time $s$ and let $w_{l}\left(z_{l}, s\right)$ be the payoffs of a leader $z_{l}$ enjoying $s$ helping time from her

helper. Without managers, total surplus is split among the riders so that $Y\left(z_{l}, z_{h}, s\right)=w_{h}\left(z_{h}, s\right)+w_{l}\left(z_{l}, s\right)$. It is further assumed that riders maximize their own payoffs.

\section{$2.2 \quad$ Feasible teams}

Some general results about feasible teams are helpful to characterize the equilibrium of this model. First, it can be shown that Proposition 3 is true under SA I and SA II.

Proposition 3 Under SA I and SA II, the surplus of all feasible teams 
$\left(z_{l}, z_{h}\right) \in Z^{2}$, with $z_{l} \geq z_{h}$, is maximized when $z_{l}$, i.e. the most able rider, becomes the leader and $z_{h}$, i.e. the least able rider, becomes the helper.

\section{Proof. See Appendix B}

The intuition is the following. From SA I.2, the net gain of velocity in a team $\left\langle z_{l}, z_{h}\right\rangle$ is larger if the best rider is re-assigned from being the helper to being the leader. Hence, as long as rewards are convex as stated in SA II.3, a team's surplus is greater when the less able rider helps the most able one. Denoting $\gamma\left(z_{l}, z_{h}\right)$ the transportation $\operatorname{plan}^{8}$ connecting helpers to leaders in equilibrium, from Proposition 3 we already know that $\gamma\left(z_{l}, z_{h}\right)=0$ for $z_{l}<z_{h}$.

Another interesting pattern of the model is the strategy within teams. How much help intensity to ask/offer? To answer this question, first note that, within teams, riders will always choose $s$ so as to maximize their team's surplus, i.e. $s^{*}\left(z_{l}, z_{h}\right)=\arg \max _{s} Y\left(z_{l}, z_{h}, s\right)$. Indeed, suppose that both riders choose $s^{0} \neq s^{*}\left(z_{l}, z_{h}\right)$ and that the helper receives payoffs $w_{h}^{0}$ and the leader payoffs $w_{l}^{0}=Y\left(z_{l}, z_{h}, s^{0}\right)-w_{h}^{0}$. Since by definition $Y\left(z_{l}, z_{h}, s^{0}\right) \leq$ $Y\left(z_{l}, z_{h}, s^{*}\left(z_{l}, z_{h}\right)\right)$, both riders could increase their team's surplus by set-

\footnotetext{
${ }^{8}$ The transportation plan $\gamma(x, y)$ is the density of equilibrium pairs formed with a leader of ability $x$ and a helper of ability $y$.
} 
ting $s=s^{*}\left(z_{l}, z_{h}\right)$. Splitting the additional surplus $Y\left(z_{l}, z_{h}, s^{*}\left(z_{l}, z_{h}\right)\right)-$ $Y\left(z_{l}, z_{h}, s^{0}\right)$ among them will increase both riders' payoffs. For all feasible teams, we therefore always have $s=s^{*}\left(z_{l}, z_{h}\right)$. The arguments of $s^{*}$ will be dropped when unambiguous.

Under our standing assumptions, the following proposition shows that the decision about how much helping time to provide simplifies considerably for all feasible teams.

Proposition 4 Under $S A I$ and $S A$ II, for all feasible teams $\left(z_{l}, z_{h}\right) \in$ $Z^{2}$, with $z_{l} \geq z_{h}$, optimal helping time $s^{*}\left(z_{l}, z_{h}\right)$ is strictly convex so that $s^{*}\left(z_{l}, z_{h}\right)=\left\{\begin{array}{c}1 \text { iff } Y\left(z_{l}, z_{h}, 1\right)>Y\left(z_{l}, z_{h}, 0\right) \\ 0 \text { otherwise }\end{array}\right.$.

Proof. See Appendix B

Intuitively, the convexity of the reward function in assumption SA II.3 carries on to the relationship between teams' surplus and helping time as long as helping time is efficient and $a>0$ as in SA I.1. In other words, if $v$ is sufficiently convex given $f$ and $a$, then for all feasible teams $s^{*}\left(z_{l}, z_{h}\right)=1$. Reciprocally, if $f$ is sufficiently small relative to $a$ given $v$, then for all feasible teams $s^{*}\left(z_{l}, z_{h}\right)=0$.

Finally, for notational convenience, note that, since from Proposition 4, $s^{*}=1$ if $Y\left(z_{l}, z_{h}, 1\right)>Y\left(z_{l}, z_{h}, 0\right)$ and 0 otherwise, the surplus of a team can 
be written as:

$$
Y\left(z_{l}, z_{h}, s^{*}\right)=s^{*} \times Y_{1}\left(z_{l}, z_{h}\right)+\left(1-s^{*}\right) Y_{0}\left(z_{l}, z_{h}\right)
$$

where $Y_{1}\left(z_{l}, z_{h}\right)=v\left(z_{l}+f\left(z_{h}\right)\right)+v\left(z_{h}(1-a)\right)$ and $Y_{0}\left(z_{l}, z_{h}\right)=v\left(z_{l}\right)+v\left(z_{h}\right)$.

Similarly, the payoffs functions can be written as:

$$
w_{i}\left(z_{i}, s^{*}\right)=s^{*} \times w_{i 1}\left(z_{h}\right)+\left(1-s^{*}\right) \times w_{0}\left(z_{h}\right), i=h, l,
$$

where $w_{0}(z)$ are the payoffs of an individual rider. Hence, $w_{0}(z)=v(z)$ independently of the ability of his team mate.

\subsection{Riders' problem}

Riders maximize their payoffs. The problem of a rider $z$ is therefore to choose the role (leader, helper or individual rider) that maximizes her payoffs:

$$
\max \left\{w_{l 1}(z), w_{h 1}(z), v(z)\right\}
$$

The leader's problem is to find a helper $z_{h}$ that maximizes her payoffs. 
This problem reads as: ${ }^{9}$

$$
\max _{z_{h}}\left[Y_{1}\left(z_{l}, z_{h}\right)-w_{h 1}\left(z_{h}\right)\right]
$$

The first order condition to the leader's problem yields:

$$
w_{h 1}^{\prime}\left(z_{h}\right)=v^{\prime}\left(z_{l}+f\left(z_{h}\right)\right) f^{\prime}\left(z_{h}\right)+(1-a) v^{\prime}\left(z_{h}(1-a)\right)>0
$$

From our standing assumptions SAI and SAII we already know that the equilibrium payoffs function for helpers is strictly increasing in helpers' ability. ${ }^{10}$

Symmetrically, the helper's problem is to find a leader $z_{l}$ that maximizes her payoffs. This problem reads as:

$$
\max _{z_{h}}\left[Y_{1}\left(z_{l}, z_{h}\right)-w_{l 1}\left(z_{l}\right)\right]
$$

\footnotetext{
${ }^{9}$ We refer the reader to Appendix A for a formal presentation of the second order conditions to the leader's and helper's optimization problem.

${ }^{10}$ As shown in Appendix A, the second order conditions to the riders' problem also indicates that the payoffs functions are strictly convex.
} 
The first order condition to this problem is:

$$
w_{l 1}^{\prime}\left(z_{l}\right)=v^{\prime}\left(z_{l}+f\left(z_{h}\right)\right)>0
$$

From our standing assumptions SAI and SAII, it follows that the equilibrium payoffs function for leaders is strictly increasing in leaders' ability.

The first order conditions pin down the slopes of the payoff functions. The level of these two functions $w_{l 1}(\underline{z})$ and $w_{h 1}(\underline{z})$ together with the slopes will determine the set $H \subseteq Z$ of riders for which $w_{h 1}(z)=\max \left\{w_{l 1}(z), w_{h 1}(z), v(z)\right\}$ (the set of helpers), the set $L$ of riders for which $w_{l 1}(z)=\max \left\{w_{l 1}(z), w_{h 1}(z), v(z)\right\}$ (the set of leaders) and the set $I \equiv Z \backslash H \cup L$ of riders for which $v(z)=$ $\max \left\{w_{l 1}(z), w_{h 1}(z), v(z)\right\}$ (the set of individual riders).

Note here that $w_{l 1}^{\prime}\left(z_{l}\right)-v^{\prime}\left(z_{l}\right)>0$ for all $z_{l} \in Z$ under SA I and SA II, while without further restrictions on the primitives of the model, it is impossible to conclude about the sign of $w_{h 1}^{\prime}\left(z_{h}\right)-v^{\prime}\left(z_{h}\right)$. 


\subsection{Equilibrium}

Let $L \subseteq Z$ be the set of leaders and $H \subseteq Z$ be the set of helpers. ${ }^{11}$ Let $\gamma\left(z_{l}, z_{h}\right)$ with $z_{l} \in L$ and $z_{h} \in H$ be a transportation plan.

Definition 5 A feasible assignment in this economy is a tuple $(L, H, \gamma)$ so that:

1. $\gamma\left(z_{l}, z_{h}\right) \geq 0$ for all $\left(z_{l}, z_{h}\right) \in L \times H$

2. $\int_{H} d \gamma\left(z_{l}, z_{h}\right)=D\left(z_{l}\right), \forall z_{l} \in L,{ }^{12}$

3. $\int_{L} d \gamma\left(z_{l}, z_{h}\right)=D\left(z_{h}\right), \forall z_{h} \in H$,

4. $\int_{H} d D\left(z_{h}\right) \equiv D(H)=D(L) \equiv \int_{L} d D\left(z_{l}\right)$.

Let $\Lambda$ be the set of feasible assignments and let $\Gamma_{L \times H}$ be the set of feasible transportation plans given sets $L$ and $H$. In other words, the set $\Gamma_{L \times H}$ is the set of measures whose marginals are $D(H)$ and $D(L)$ respectively.

Definition 6 An equilibrium in this economy consists of:

\footnotetext{
${ }^{11}$ Note that we do not impose the set of leaders and helpers to be disjoint. Self-matches could indeed arise in equilibrium if $Y_{1}(z, z) \geq 2 v(z)$.

${ }^{12}$ Note that conditions 2 and 3 take into account the possibility that $H$ and $L$ are not disjoint sets. In this case, self-matches arise in the interval $H \cap L$ and one (randomly chosen) rider become the leader and the other the helper.
} 
- two payoffs functions $w_{h 1}\left(z_{h}\right)$ and $w_{l 1}\left(z_{l}\right)$ and,

- a feasible assignment $(L, H, \gamma)$ so that:

- riders choose a role (helper, leader or individual rider) and their eventual leader or helper so as to maximize their own payoffs.

The following two propositions show important characteristics of the equilibrium assignment.

Proposition 7 Under SA I and SA II, in equilibrium, more able leaders are matched with more able helpers.

Proof. See Appendix B

This result essentially follows from the convexity of the reward function $v$ and the fact that better helpers also happen to be better riders.

Proposition 8 Under SA I and SA II, there is the following stratification in equilibrium: i) there are no leaders of ability lower than $z^{\left(l_{1}\right)}$ and ii) there are no individual riders of ability higher than $z^{\left(l_{1}\right)}$.

\section{Proof. See Appendix B}

Several special cases are worth noting. First, suppose that $z^{\left(l_{1}\right)}>\bar{z}$. In that case, all riders prefer riding individually than becoming a leader. 
Since, there are no leaders there cannot be any helper either. All riders ride individually. This case arises when $v($.$) is not convex enough given f($.$) and$ $a$.

Second, suppose that $z^{\left(l_{1}\right)}<\underline{z}$. This means that all riders prefer riding individually than becoming a helper. Since there are no helpers there cannot be any leader either. All riders ride individually.

Finally, as soon as $z^{\left(l_{1}\right)} \in(\underline{z}, \bar{z})$, there will be intervals of helpers and leaders. In particular, a perfectly stratified equilibrium could arise. We could have for instance riders of ability $z \in\left[\underline{z}, z^{\left(l_{1}\right)}\right)$ becoming individual riders, riders $\left.z \in z^{\left(l_{1}\right)}, z^{\left(l_{2}\right)}\right]$ becoming helpers and riders of ability $z \in\left[z^{\left(l_{2}\right)}, \bar{z}\right]$ becoming leaders. Similarly, we could have a stratification where riders of ability $z \in\left[\underline{z}, z^{\left(h_{1}\right)}\right]$ become helpers, riders of ability $z \in\left[z^{\left(h_{1}\right)}, z^{\left(l_{1}\right)}\right]$ become individual riders and riders of ability $z \in\left[z^{\left(l_{1}\right)}, \bar{z}\right]$ become leaders.

\subsection{Existence, uniqueness and optimality}

To study the properties of an equilibrium in this economy it is useful to write the social planner's problem associated. This problem reads as:

$$
\max _{(L, H, \gamma) \in \Lambda} \int_{L \times H} Y_{1}\left(z_{l}, z_{h}\right) d \gamma\left(z_{l}, z_{h}\right)+\int_{Z \backslash H \cup L} v(z) d D(z)
$$


We first show that an optimal assignment $(L, H, \gamma)$ exists.

Proposition 9 Under $S A$ I and $S A$ II, an optimal assignment $(L, H, \gamma)$ exists.

Proof. First note that $\int_{Z \backslash H \cup L} v(z) d D(z)$ does not depend on $\gamma$ but merely on the feasible sets $L$ and $H$. Hence, given the sets $L$ and $H$, the problem simplifies to:

$$
\max _{\gamma \in \Gamma_{L \times H}} \int_{L \times H} Y_{1}\left(z_{l}, z_{h}\right) d \gamma\left(z_{l}, z_{h}\right)
$$

This is the classical Monge-Kantorovich transportation problem. Theorem 4.1 in Villani (2009) indicates that if i) $Y_{1}\left(z_{l}, z_{h}\right)$ is upper semicontinuous and ii) $\Gamma_{L \times H}$ is compact then there exists an optimal $\gamma$ in this problem (conditional on $L \subseteq Z$ and $H \subseteq Z$ in our case).

Condition i) is met since from SA I and II, $Y_{1}\left(z_{l}, z_{h}\right)$ is continuous. Condition ii) is also met. To see this, note that since $Z$ is compact, $H$ and $L$ are also compact so that $D(z)$ for all $z \in H$ and $D(z)$ for all $z \in L$ are tight. It follows from Lemma 4.4 in Villani (2009) that $\Gamma_{L \times H}$ is also tight and hence compact by Prokhorov's Theorem. Condition ii)therefore holds.

As a result, for each pair of feasible sets $L$ and $H$, there exists an optimal transportation plan, say $\gamma_{L \times H}^{*}$. Since the sets $(L, H)$ of feasible helpers and 
leaders is compact, we conclude that there exists an optimal assignment $\left(L, H, \gamma_{L \times H}^{*}\right)$ solution of:

$$
\max _{(L, H) \in Z^{2}} \int_{L \times H} Y_{1}\left(z_{l}, z_{h}\right) d \gamma_{L \times H}^{*}+\int_{Z \backslash H \cup L} v(z) d D(z)
$$

As noted in the proof of Proposition 9, the social planner's problem is in fact related to the Primal Program of the Monge-Kantorovich transportation problem. The associated dual program is:

$$
\begin{gathered}
\min _{w_{l}, w_{h}} \int_{Z} w_{l}(z) d D(z)+\int_{Z} w_{h}(z) d D(z) \\
\text { s.t. } \\
w_{i}(z) \geq v(z) i=h, l \text { (i) } \\
w_{l}\left(z_{l}\right)+w_{h}\left(z_{h}\right) \geq Y_{1}\left(z_{l}, z_{h}\right) \text { for all } z_{l}, z_{h} \in Z^{2} \text { (ii) }
\end{gathered}
$$

Constraint i)in the dual program corresponds to the condition of individual rationality (riders always have the option of remaining unmatched). Constraint ii) guarantees that an outcome is not blocked by any coalition. If 
ii) is not satisfied, a pair $z_{l}$ and $z_{h}$ can always break up and reunite splitting $Y_{1}\left(z_{l}, z_{h}\right)$ in such a way that both are better off $\left(z_{l}\right.$ gets more than $w_{l}\left(z_{l}\right)$ and $z_{h}$ gets more than $\left.w_{h}\left(z_{h}\right)\right)$.

A fundamental theorem of duality asserts that a feasible tuple $\left(\left(w_{h}, w_{l}\right), \gamma\right)$ produces $\int_{Z} w_{l}(z) d D(z)+\int_{Z} w_{h}(z) d D(z)=\int_{L \times H} Y_{1}\left(z_{l}, z_{h}\right) d \gamma\left(z_{l}, z_{h}\right)+\int_{Z \backslash H \cup L} v(z) d D(z)$ iff $\gamma\left(z_{l}, z_{h}\right)$ solves the primal program and $\left(w_{h}(z), w_{l}(z)\right)$ solves the dual program.

This result allows us to prove the following proposition.

Proposition 10 A feasible tuple $\left(\left(w_{h}(z), w_{l}(z)\right), \gamma\right)$ that solves both the primal and dual program maximizes riders payoffs.

Proof. Suppose that $\left(w_{h}(z), w_{l}(z)\right)$ solves the dual program and $\gamma$ solves the primal program. Then,

$$
\int_{Z} w_{l}(z) d D(z)+\int_{Z} w_{h}(z) d D(z)=\int_{L \times H} Y_{1}\left(z_{l}, z_{h}\right) d \gamma\left(z_{l}, z_{h}\right)+\int_{Z \backslash H \cup L} v(z) d D(z)
$$


and hence:

$$
\begin{aligned}
w_{h}\left(z_{h}\right)+w_{l}\left(z_{l}\right)= & Y_{1}\left(z_{l}, z_{h}\right) \text { for } \gamma-\text { a.e. }\left(z_{l}, z_{h}\right) \\
& \text { and } \\
w_{l}(z)= & w_{h}(z)=v(z) \text { for } d-\text { a.e. } z \in Z \backslash H \cup L
\end{aligned}
$$

Take a leader $z_{l}^{*} \in L$ that is matched with a helper $z_{h}^{*} \in H$ in equilibrium (i.e. so that $\left.\gamma\left(z_{l}^{*}, z_{h}^{*}\right)>0\right)$. The riders of this team get respectively $w_{h}\left(z_{h}^{*}\right)=$ $Y_{1}\left(z_{l}^{*}, z_{h}^{*}\right)-w_{l}\left(z_{l}^{*}\right)$ and $w_{l}\left(z_{l}^{*}\right)=Y_{1}\left(z_{l}^{*}, z_{h}^{*}\right)-w_{h}\left(z_{h}^{*}\right)$. Since $\left(w_{h}(z), w_{l}(z)\right)$ solves the dual program, the feasibility constraints are satisfied so that $w_{l}\left(z_{l}^{*}\right) \geq$ $Y_{1}\left(z_{l}^{*}, z_{h}\right)-w_{h}\left(z_{h}\right)$ for all $z_{h} \in Z$ and $w_{h}\left(z_{h}^{*}\right) \geq Y_{1}\left(z_{l}, z_{h}^{*}\right)-w_{l}\left(z_{l}\right)$ for all $z_{l} \in Z$. It follows that helper $z_{h}^{*}$ maximizes the payoffs of leader $z_{l}^{*}$ and leader $z_{l}^{*}$ maximizes the payoffs of helper $z_{h}^{*}$.

A direct corollary of Proposition 10 is:

Corollary 11 The pair of payoffs functions $\left(w_{l}, w_{h}\right)$ that maximizes riders' payoffs is Pareto Optimal.

Proof. A feasible tuple $\left(\left(w_{h}(z), w_{l}(z)\right), \gamma\right)$ that solve the primal and dual program maximizes riders' payoffs from Proposition 10. Since $\gamma$ solves the primal program (the social planner's problem), the pair of equilibrium payoffs 
$\left(w_{l}, w_{h}\right)$ maximizing riders payoffs also maximizes social welfare.

\subsection{Comparative statics}

In an economy without coordination (where helping time is 0 for all teams), performance inequality will be lower, measuring inequality by the range. This result is obvious for two reason. First, from Proposition 3, in an economy with coordination within teams, the most able rider becomes leader of the team. Second, from Proposition 8, there is a stratification so that at the top of the distribution of ability, riders either become leaders or helpers. Combining these two results indicate that the most able riders in this economy must necessarily be leaders. The performance at the top of the distribution in this economy must therefore be larger ceteris paribus than in the economy without coordination. Similarly, from proposition 8 we know that riders at the bottom of the distribution of ability either become a helper or ride on their own. Hence the performance at the bottom of the distribution of ability is at most equal to that of a ceteris paribus same economy without teams. It follows that the range will be larger in the economy with teams ceteris paribus. 


\section{Empirical evidence}

\subsection{Organization}

Team organization in road cycling racing

Road cycling racing is an individual sport where the first to cross the finish line wins. However, unlike most individual sports, road cycling riders have traditionally been grouped into teams (usually 9 riders). Teams' tactics (organization) has become an important aspect of the sport. Tactics turns out to be inherent in this sport since the aerodynamic benefit of drafting, following as closely as possible the slipstream of the rider in front, can save as much as $40 \%$ of the energy compared to riding alone. Some teams therefore designate a leader and have the remaining riders serve as a "wind shield" for their leader to spare energy until critical moments of the race (final climb during a mountain stage for instance). Helpers also play the role of a donkey during races, carrying food and water to their leader, or exchange their wheels or even bike in case of a mechanical problem of their leader during the course. The organization of teams is especially important during stage races.

History $^{13}$ of the Tour de France

${ }^{13}$ See McGann and McGann (2006) for a detailed account of the history of the Tour de 
The Tour de France constitutes the single most important event in road cycling racing. ${ }^{14}$ The first Tour de France took place in 1903, as an attempt from the French journal "L 'Auto" to boost its sales, and has been taking place every July ever since. ${ }^{15}$ Since the end of World War II, the Tour consists of a three weeks competition covering about 3,500 kilometers in 20 to 22 stages, including individual or team time trials and mountain stages.

Originally, and similarly to most other single-day races of the season (such as the oldest race Liège-Bastogne-Liège), the first Tours were opened to all riders and most of them were enrolled in trade teams. However, the organizer of the Tour, Henri Desgrange, insisted that while riders could compete in the name of their sponsors, no cooperation or tactics would be allowed between these riders. Henri Desgrange, who set the first World Hour Record, wanted the Tour to be The ultimate test for a rider's endurance and character and remain an individual achievement. According to Henri Desgrange, riders ought to consider everyone as a rival whether they had the same sponsor or not. However, in 1929, the Belgian rider Maurice De Waele, sponsored by the

\footnotetext{
France.

${ }^{14}$ In 2008 , the winner of the Tour de France received $€ 450,000$ in prize money or 5 times more than the winner of the Giro $(€ 90,000)$. That year, the total prize money distributed on the Tour de France amounted to $€ 3,269,760$ or 2.4 times more than on the Giro $(€ 1,380,010)$.

${ }^{15}$ Except for breaks during World War I and World War II.
} 
French bicycle company Alcyon, won the Tour with the "illegal" help of his team mates even though he was ill. This event marked Henri Desgrange, "My Tour has been won by a corpse," and led him to deny participation to trade teams, only national and regional teams were allowed from 1930 until 1961. The hierarchical organization within teams became more difficult since most riders belonged to rival trade teams for the rest of the season. The loyalty of riders was sometimes questionable, within and between teams, leading to an inefficient organization as can testimony several famous events. ${ }^{16}$

This situation was hard to accept for sponsors since they paid the salaries of riders the whole year long but were denied publicity from the season's major event. ${ }^{17}$ At the beginning of the 1960s, sales of bicycles had fallen dramatically and as the media exposure of the Tour was growing bigger thanks to live television broadcast, ${ }^{18}$ sponsors (predominantly cycles manufacturers) pressured the organizers to come back to trade teams. By the end of the

\footnotetext{
${ }^{16}$ In 1959, the french team was made up of many strong riders such as Raphaël Géminiani, Henri Anglade and Jacques Anquetil. The French team was full of internal rivalries. Part of team decided to help spanish rider Federico Bahamontes win rather than Henri Anglade in the hope to win more fees during the post-Tour criteriums as Bahamontes was a much poorer rider on flat closed circuits than Anglade.

${ }^{17}$ Trades were partly accommodated for with the authorization for the riders to put their respective trades name on their jersey and the introduction of the caravan. The caravan consists in a trade parade preceding the riders during the tour de France. This caravan is praised by the spectators and reached an height between the 30s and the 60s.

${ }^{18}$ The first live coverage from the side of the road was from the Aubisque, one of the most famous climb in the Pyrenees, on July $8^{\text {th }}, 1958$.
} 
1960s, trade teams were back in and for good.

The media exposure of the Tour de France has grown ever since and so have the stakes. Figure 1 shows the evolution of the total prize money, corrected for inflation, distributed on the Tour since 1950. The total prize money were roughly steady from 1950 to 1971 and started increasing ever since, at 3\% per year between 1971 and 1985 and 5\% thereafter. Another remarkable evolution has been the evolution of the share of these prizes attributed to the winner in the final classification as shown in Figure 2. The average share of prizes allocated to the winner was about $4.5 \%$ between 1950 and 1975. It increased to an average of $6.8 \%$ between 1975 and 1985. Since 1985 , the winner goes home with about $15 \%$ of the total amount of money prizes distributed during the Tour de France. ${ }^{19}$

We argue that up until the end of the 1960s, the organization within teams was initially limited while since then, for the many reasons mentioned above (from national teams to trade teams, media exposure (intrinsic utility), increasing stakes and convexification of the payoffs by rank), the organization of teams has progressively changed towards more specialization and more helping intensity of helpers towards their leaders.

\footnotetext{
${ }^{19}$ It should be noted that the prizes won by each rider of a team are usually pooled together and redistributed within the team.
} 
This makes the Tour de France a very well-suited market to investigate the link between team organization and performance inequality. Indeed, the organization structure of road cycling resembles that of many industries with an implicit market for productive time. However, in contrast to most of these industries, road cycling in the Tour de France presents a clear change in the structure of incentives that allows us to appreciate and evaluate the impact of the hierarchical organization on, in particular, inequality. Another advantage of the Tour de France is that road cycling offers the possibility to observe directly productivity via the velocity (average speed during the race) of each rider. ${ }^{20}$ Using the example of the tour de France, it is possible 1) to detect if hierarchical organization has or not an impact on inequality compared to autarky and 2) to evaluate the relative effect of hierarchical effect vs. globalization on equality.

\subsection{Inequality}

Figures 3 shows the evolution of the velocity distribution over time in the final classification of the Tour de France. The figure clearly indicates a surge in inequality, represented here by the volatility of the velocity distribution.

\footnotetext{
${ }^{20}$ Faster riders are ranked first and earn higher premia for their team.
} 
This movement appears at the end of the 1960s. It is noticeable that this inflection turns out to be synchronous to the authorization of trade teams to participate and the increase in the prize money distributed.

To have a better insight of this remarkable development, we have also represented in Figure 4 the evolution of the velocity density over time and in Figure 5 the evolution of the cumulative distribution of velocity. Interestingly enough, it appears in Figure 4 that the higher velocity inequality takes the form of a progressive modification of the shape of the distribution. While it was unimodal for the 1950s and 1960s, it progressively moves to a bimodal shape from the 1970s on. This indicates that a small group of top riders have improved their velocity (relative to the contemporaneous mean velocity) while the bulk of the riders have seen their performance deteriorate. Hence the inequality within the peloton is rising but in a very peculiar way. Figure 5 confirms this ${ }^{21}$ but also informs us about the proportion of riders that have increased their performance relative to the contemporaneous mean velocity. This part can be found as the fixed point of the CDF and roughly corresponds to $0.6-0.7$. This means that $30-40 \%$ of the riders improved their performances relative to the contemporaneous mean.

\footnotetext{
${ }^{21}$ The twist of the cumulative distribution over time indicates the movement towards bimodality.
} 
Figures 4 and 5 clearly indicate that inequality has strongly increased in the peloton of the Tour de France since the end of 1960s. Our intuition is that the modification of the organization of teams impacted positively the inequality. In the empirical part of the paper that follows, we test this hypothesis against alternative explanations such as the internationalization of riders, technological development and difficulty.

\subsection{Empirical analysis}

\subsubsection{Data}

For the empirical exercise, our main source of data is from http://www.tourgiro-vuelta.net/, a website managed by Michiel van Lonkhuyzen. To correct for eventual mistakes or/and omission (a few distances and winning times), we cross checked with additional sources, in particular Wikipedia for the total distance and the winning time and http://www.ledicodutour.com/ for the general classification of the tour de France. Our database covers the Tour de France for the period 1947-2008, i.e. 62 observations. 


\subsubsection{Methodology}

For each participant appearing in the final classification of any Tour, we calculate his average velocity as the total distance of the tour divide by his finishing time. This enables us to derive a distribution of velocity for each tour as well as its associated measures of volatility. In particular, we consider the range (velocity of the winner - velocity of the last rider) that constitutes an efficient estimate of volatility at time t (Parkinson, 1980). ${ }^{22}$ For robustness purposes we also consider the range at specific parts of the distribution. The reduced range, defined as the difference between the volatility of the top and bottom $5 \%$ riders, is considered in order to control for extreme behavior: the high volatility observed in some year could be due to exceptional cluster of gifted riders such as the couple Hinault and Lemond in 80's or Armstrong and Ulrich in the early 2000's. Similarly, asymmetric ranges (upper and lower) are introduced to disentangle the factors affecting the leaders and the helpers. These fours variables (range, restricted range, upper range and lower range) constitute the dependent volatility variables to be explained.

The first candidate to explain the rise in overall inequality which forms our main hypothesis, is specialization: an increase in help intensity provided

\footnotetext{
${ }^{22}$ More precisely he showed that $\frac{\text { Range }_{t}^{2}}{4 \ln 2}$ converges to the spot volatility at time t.
} 
by helpers to their leaders hence sacrificing their own velocity to the profit of that of their leaders. To this aim, we consider a proxy of spot volatility within team. This within team volatility is proxied by the range within team (denoted as specialization). A positive sign in the regression would indicate that a higher specialization within team increases the volatility of the whole distribution.

The second candidate to explain a change in volatility is internationalization. While early on, participants of each Tour were primarily French or from a core country (Belgium, the Netherlands, Luxembourg and Switzerland), in 2008, 38 nationalities were represented at the start of the Tour de France. This dramatic globalization of the sport might have lead to an increase in the volatility of the velocity. To capture the potential effect of globalization, we consider 5 variables: i) the percentage of riders from the core countries (1-globalization), ii) from France (\%French), iii) from Italy (\%Italian), iv) from Spain (\%Spanish), and v) the number of nationalities represented at the start of each tour (number nat.).

The third candidate is technological development. While it is indisputable that technology has changed the sport and improved velocity, one might argue that it has had an heterogenous treatment effect improving velocity 
of higher ability riders relatively more and hence increasing the volatility of velocity. We define technological progress loosely as the type of bicycle and gear used, training methods and nutrition. We try and capture the effect of technological progress by including a trend in the regression and allowing for potential structural breaks in it by applying the Bai and Perron's (1998) test.

Finally, we added several other control variables such as the difficulty of a particular tour (as proxied by the failing rate, i.e. the percentage of riders finishing), the direction of the tour de France (Pyrenees before or after the Alps) and the percentage of riders participating for the first time.

\subsubsection{Results}

We estimate the following model using OLS technique.

$$
T R_{t}^{j}=\alpha_{0}+\alpha_{1} W R_{t}+X_{t} \beta+u_{t}
$$

where $T R_{t}^{j} \in\{$ Range, reduced Range, lower Range, Upper Range $\}, W R_{t}$ is the within team range at Tour $t$ and $X_{t}$ are control variables including a time trend, the number of countries represented, the percentage of French riders, the percentage of Spanish riders, the percentage of Italian riders, the 
percentage of riders from one of the core countries and a measure of the difficulty of the Tour. $u_{t}$ is a random shock.

Misspecification tests for autocorrelation (LM of Godfrey, 1978), heteroscedasticity (Breusch-Pagan, 1979), normality (Jarque and Bera, 1980) and structural break (Chow test with an unknown break date à la Andrews, 1993) are performed and support the idea of a correct specification. Furthermore, the presence of a unit root has been tested for each endogenous variable and rejected. ${ }^{23}$

The main results of our four regressions are reported in Tables 1 . The adjusted R-squares providing information on the quality of the regressions are extremely high (higher than $80 \%$ ) for all range variables except for the lower range (around 60\%). Our set of variables seems to constitute an adequate space to analyze the volatility. More importantly, the signs of the estimators are in line with our theoretical model. For all measures of overall volatility considered, the volatility within team has a positive impact. This result provides a strong support for specialization as an explanation for the rise in performance inequality among riders in the tour de France. Another remarkable result is that not only the sign but also the magnitude of the

\footnotetext{
${ }^{23}$ All the tests are available upon request from the authors.
} 
elasticity is robust to our choice of volatility, ${ }^{24}$ ranging from 0.48 to 0.65 .

Regarding the other candidates, we notice that although Globalization has the right sign (negative: a higher percentage of core countries riders induces a lower volatility), it has a lower impact and is not significant. Finally, the other four variables, i.e. percentage of riders from France (\%French), from Italy (\%Italian), from Spain (\%Spanish), and the number of nationalities represented in the tour (number nat.) are also not significant. The trend, representing the technological progress in a wide sense, is not significant. A similar result holds for the difficulty variable. ${ }^{25}$ To summarize our results, it appears that hierarchical organization is the key variable that explains the rise in productivity inequality in the Tour de France. ${ }^{26}$

\subsection{Can the model reproduce the stylized facts?}

To evaluate the empirical prediction of the model, we propose the following test for the impact of hierarchies on productivity inequality. Consider $N$

\footnotetext{
${ }^{24}$ It is noticeable that a simple t-test would lead to not reject the equality between these coefficients.

${ }^{25}$ We only report here the results for the difficulty variable. All other appear as not significant but are not reported to save space. They are available upon request from the authors.

${ }^{26}$ To assess the robustness of our results, the same empirical analysis is performed for the Italian Giro and the Spanish Vuelta. Results are available in Addendum 1. It turns out that findings are similar to those obtained for the Tour de France.
} 
teams and suppose that each team has only one leader and all 9 riders of each team finish the tour. We also assume that initially, riders are assigned at random to teams and help intensity is zero for every rider (autarky). This means that the final classification reflects the true distribution of ability. In particular, the velocity of the $N^{t h}$ rider relative to that of the $N+1^{\text {th }}$ rider reflects their ability differential. Following, for instance, a convexification of the reward function, suppose that the new equilibrium exhibits a strict stratification of riders: all $N$ leaders are strictly better than any of the $8 \times N$ helpers. In the final classification, the first riders are the leaders of the various teams and the last $8 \times N$ riders are their helpers (or riders riding individually). The performance of all leaders increases while the performance of all helpers decreases holding everything else constant. The model has three important predictions. First, the within team range increases in all teams. Second, the overall range increases too. Third and most importantly, the performance of the $N^{\text {th }}$ rider (the least able leader) increases while the performance of the $N+1^{\text {th }}$ rider (the best helper) decreases. This means that at constant distribution of ability, we should observe a movement of riders above the $100 \times\left(1-\frac{N}{9 N}\right)=100 \times \frac{8}{9} \approx 90^{t h}$ quantile away from riders below the $90^{\text {th }}$ quantile. 
Figure 5 clearly shows that the distribution becomes more unequal over time but it is striking to see that all curves in all panels seem to be twisting clock wise with a twisting point at the $60^{\text {th }}$ quantile. Although the model would have predicted this pattern with a twisting point at the $90^{\text {th }}$ quantile, one should bear in mind that 1) we have assumed a strict stratification which is only a special case in the economy depicted above and 2) the model depicts economies without performance shocks (no sickness during the tour, no falls, no exclusion for doping etc.) and with perfect information about ability for all riders. With this in mind, we take the results presented in Figure 5 as supporting our hypothesis that the increase in the volatility of velocity is

primarily due to an increase in the hierarchical organization of the team and help intensity.

\section{Conclusion}

This paper investigates the relationship between hierarchical organization and performance inequality within and between organizations. An equilibrium theory of the organization of work in an economy with an implicit market for productive time is first presented. In this economy, agents have 
limited productive time and can choose to produce in autarky, buy productive time from helpers to increase own production or, sell their productive time to a leader and thereby give up own production. This implicit market gives rise to the formation of teams, organized in hierarchies with one leader at the top and helpers below. We prove that an equilibrium exists and is efficient and show that relative to autarky, hierarchical organization leads to higher within and between team payoffs/productivity inequality.

To illustrate the main prediction of our theoretical model, i.e. team organization increases performance inequality, we propose an empirical analysis in the context of professional road cycling. Considering such a framework is novel in this literature and has several key advantages compared to other markets that make road cycling the most appropriated framework to study the existence of an implicit market for productive time. The two main key advantages of road cycling relative to other economies (i.e. layer suits as used by Garicano and Hubbard, 2009) is that i) road cycling exhibits a clear change in the incentives to organize work within team since the end 60 's and ii) a direct measure of individual productivity is available in that sector via riders' velocity. Range regressions's results robustly show that leaders' velocity increased significantly (economically and statistically) more than that 
of helpers, supporting hence the model's prediction of a positive relationship between hierarchical organization and productivity inequality.

\section{References}

Andrews, D. (1993): "Tests for Parameter Instability and Structural Change with Unknown Change Point," Econometrica, 61(4), 821-56.

Bai, J., and P. Perron (1998): "Estimating and Testing Linear Models with Multiple Structural Changes," Econometrica, 66(1), 47-78.

Becker, G. S. (1973): "A Theory of Marriage: Part I," Journal of Political Economy, 81(4), 813-46.

Breusch, T. S., and A. R. Pagan (1979): "A Simple Test for Heteroscedasticity and Random Coefficient Variation," Econometrica, 47(5), $1287-94$.

Garicano, L., and T. Hubbard (2009): "Earnings Inequality and Coordination Costs: Evidence From U.S. Law Firms," NBER Working Papers 14741, National Bureau of Economic Research, Inc. 
Garicano, L., and E. Rossi-Hansberg (2006): "Organization and Inequality in a Knowledge Economy," The Quarterly Journal of Economics, 121(4), 1383-1435.

Godfrey, L. G. (1978): "Testing for Higher Order Serial Correlation in Regression Equations When the Regressors Include Lagged Dependent Variables," Econometrica, 46(6), 1303-10.

Jarque, C. M., And A. K. Bera (1980): "Efficient tests for normality, homoscedasticity and serial independence of regression residuals," Economics Letters, 6(3), 255-59.

McGann, B., And C. McGann (2006): The Story of the Tour de France: volume 1 and 2. Dog Ear Publishing.

PARKInSON, M. (1980): "The extreme value method for estimating the variance of the rate of return," Journal of Business, 53(1), 65-65.

Rosen, S. (1974): "Hedonic Prices and Implicit Markets: Product Differentiation in Pure Competition," Journal of Political Economy, 82, 34-55.

Sattinger, M. (1993): "Assignment Models of the Distribution of Earnings," Journal of Economic Literature, 31(2), 831-80. 
Tinbergen, J. (1956): "On the Theory of Income Distribution," Weltwirtschaftliches Archiv, 77(1), 156-75.

Villani, C. (2009): Optimal Transport, Old and New. Springer-Verlag Berlin Heidelberg. 


\section{Appendix A: Second order conditions:}

The second order condition to the leader's problem reads as:

$$
\begin{aligned}
w_{h 1}^{\prime \prime}\left(z_{h}\right)> & v^{\prime \prime}\left(z_{l}+f\left(z_{h}\right)\right)\left(f^{\prime}\left(z_{h}\right)\right)^{2}+v^{\prime}\left(z_{l}+f\left(z_{h}\right)\right) f^{\prime \prime}\left(z_{h}\right)+(1-a)^{2} v^{\prime \prime}\left(z _ { h } \left(1-\left(\beta_{3}\right)\right.\right. \\
\text { if } 0< & v\left(z_{l}+f\left(z_{h}\right)\right)-v\left(z_{l}\right)-v\left(z_{h}\right)+v\left(z_{h}(1-a)\right) \\
& \text { and } \\
w_{0}^{\prime \prime}\left(z_{h}\right)> & v^{\prime \prime}\left(z_{h}\right)>0 \text { otherwise. }
\end{aligned}
$$

Similarly, the second order condition to the helper's problem reads as:

$$
\begin{aligned}
& w_{l 1}^{\prime \prime}\left(z_{l}\right)>v^{\prime \prime}\left(z_{l}+f\left(z_{h}\right)\right) \\
& \text { if } v\left(z_{l}+f\left(z_{h}\right)\right)-v\left(z_{l}\right)> v\left(z_{h}\right)-v\left(z_{h}(1-a)\right) \\
& \text { and } \\
& w_{0}^{\prime \prime}\left(z_{l}\right)-v^{\prime \prime}\left(z_{l}\right)>0 \text { otherwise. }
\end{aligned}
$$

An important remark is that our standing assumptions SAI and SAII imply that $w_{i 1}^{\prime \prime}\left(z_{i}\right)>0$ for $i=l, h$ so that equilibrium payoffs functions are convex. 


\section{Appendix B: Proofs of propositions}

We begin with Lemma 12 that will be used in the proof of Proposition 3.

Lemma 12 Under $S A$ II, we have $v\left(x_{2}+\Delta_{2}\right)-v\left(x_{2}\right) \geq v\left(x_{1}+\Delta_{1}\right)-v\left(x_{1}\right)$ for all $x_{2} \geq x_{1} \geq 0$ and $\Delta_{2} \geq \Delta_{1} \geq 0$.

Proof. Since from SA II.2, $v^{\prime}(z)>0$ for all $z \geq 0$, it follows that $v\left(x_{2}+\Delta_{2}\right) \geq$ $v\left(x_{2}+\Delta_{1}\right)$ for all $\Delta_{2} \geq \Delta_{1} \geq 0$.

It remains to show that $v\left(x_{2}+\Delta_{1}\right)-v\left(x_{2}\right) \geq v\left(x_{1}+\Delta_{1}\right)-v\left(x_{1}\right)$ for all $x_{2} \geq x_{1} \geq 0$ and $\Delta_{1} \geq 0$.

Write $g_{\Delta}(x) \equiv v(x+\Delta)-v(x)$ with $\Delta \geq 0$. By definition we have $g_{\Delta}^{\prime}(x)=v^{\prime}(x+\Delta)-v^{\prime}(x)$.

Since $v^{\prime \prime} \geq 0$ from SA II.3, $v^{\prime}$ is increasing over $x$ so that $g_{\Delta}^{\prime}(x)=v^{\prime}(x+$ $\Delta)-v^{\prime}(x) \geq 0$. It follows that $g_{\Delta_{1}}\left(x_{2}\right)=v\left(x_{2}+\Delta_{1}\right)-v\left(x_{2}\right) \geq v\left(x_{1}+\Delta_{1}\right)-$ $v\left(x_{1}\right)=g_{\Delta_{1}}\left(x_{1}\right)$ for $x_{2} \geq x_{1}$.

Proof of proposition 3: More able riders become leaders.

Proof. Take a team of riders with respective ability $x$ and $y$ with $x \geq y$ without loss of generality. This team's surplus is $Y(x, y) \equiv \max _{s} v(x+$ $f(y) s)+v(y(1-a s))$ when $x$ is the leader and $Y(y, x) \equiv \max _{s} v(y+f(x) s)+$ 
$v(x(1-a s))$ when $y$ is the leader. To prove that $x$ will always be the leader we need to prove that $Y(x, y) \geq Y(y, x)$. Denote $s^{0}=s^{*}(y, x)=\arg \max _{s} v(y+$ $f(x) s)+v(x(1-a s))$ and denote $s^{1}=s^{*}(x, y)=\arg \max _{s} v(x+f(y) s)+$ $v(y(1-a s))$. By definition we have:

$$
Y(x, y)=v\left(x+f(y) s^{1}\right)+v\left(y\left(1-a s^{1}\right)\right) \geq v\left(x+f(y) s^{0}\right)+v\left(y\left(1-a s^{0}\right)\right)
$$

Hence, it is enough to prove that $v\left(x+f(y) s^{0}\right)+v\left(y\left(1-a s^{0}\right)\right)>v(y+$ $\left.f(x) s^{0}\right)+v\left(x\left(1-a s^{0}\right)\right)$ for all $1 \geq s^{0} \geq 0$. Rearranging terms, we aim at proving that the following inequality holds for all $s^{0}$ and $x \geq y$ :

$$
v\left(x+f(y) s^{0}\right)-v\left(y+f(x) s^{0}\right) \geq v\left(x\left(1-a s^{0}\right)\right)-v\left(y\left(1-a s^{0}\right)\right)
$$

Write $x_{1}=y\left(1-a s^{0}\right)$ and $x_{1}+\Delta_{1}=x\left(1-a s^{0}\right)$ where $\Delta_{1}=x-y+$ $a s^{0}(y-x)$ and $x_{2}=y+f(x) s^{0}$ and $x_{2}+\Delta_{2}=x+f(y) s^{0}$ where $\Delta_{2}=$ $x-y+s^{0}(f(y)-f(x))$. Note that $x_{2} \geq x_{1}$ for all $y \in Z$ and $s^{0} \in[0,1]$. Inequality 5 can be written as:

$$
v\left(x_{2}+\Delta_{2}\right)-v\left(x_{2}\right) \geq v\left(x_{1}+\Delta_{1}\right)-v\left(x_{1}\right) \text { with } x_{2} \geq x_{1}
$$


Following Lemma 12, a sufficient condition for this inequality to hold is $\Delta_{2} \geq \Delta_{1}$. Replacing $\Delta_{1}$ and $\Delta_{2}$ by their expression in terms of $x$ and $y$ and rearranging yields:

$$
\Delta_{2} \geq \Delta_{1} \Leftrightarrow a(x-y) \geq f(x)-f(y)
$$

Hence, from SA I.2 we have $v\left(x+f(y) s^{0}\right)+v\left(y\left(1-a s^{0}\right)\right) \geq v\left(y+f(x) s^{0}\right)+$ $v\left(x\left(1-a s^{0}\right)\right)$ for all $s^{0}$ and $x \geq y$. This means that $Y(x, y) \geq Y(y, x)$ for all $x \geq y$. The surplus of a team is therefore always higher when the most able rider is helped by the least able one.

Proof of Proposition 4: conditions for a corner solution of $s^{*}(x, y)$.

We begin with the proof of Lemma that will be useful to prove Proposition 4.

Lemma 13 Under $S A I$ and $S A I I$, for all feasible teams $\left(z_{l}, z_{h}\right) \in Z^{2}$, the surplus function $Y\left(z_{l}, z_{h}, s\right)$ is a strictly convex function of helping time on $s \in[0,1]$.

Proof. Take a team of riders with respective ability $x$ and $y$ and with $x \geq y$ without loss of generality. From Proposition 3, rider $x$ becomes the 
leader and rider $y$ the helper. This team's surplus is therefore $Y(x, y, s)=$ $v(x+f(y) s)+v(y(1-a s))$. The slope of the surplus with respect to helping time obtains as:

$$
\frac{\partial Y(x, y, s)}{\partial s}=v^{\prime}(x+f(y) s) f(y)-v^{\prime}(y(1-a s)) a y
$$

The curvature of the surplus with respect to helping time is given by:

$$
\frac{\partial^{2} Y(x, y, s)}{\partial s^{2}}=v^{\prime \prime}(x+f(y) s)(f(y))^{2}+v^{\prime \prime}(y(1-a s))(a y)^{2}
$$

From SA I.1 and SA II.3, we have $\frac{\partial^{2} y(x, y, s)}{\partial s^{2}}>0$. The surplus function $Y(x, y, s)$ is strictly convex on $s \in[0,1]$.

We can now prove Proposition 4.

Proof. Take a team of riders with respective ability $x$ and $y$ with $x \geq y$ without loss of generality. From proposition 3, rider $x$ becomes the leader and rider $y$ the helper. This team has surplus equal to $Y(x, y, s)=v(x+$ $f(y) s)+v(y(1-a s))$. From Lemma 13, we know that $Y(x, y, s)$ is strictly 
convex in $s$ on $s \in[0,1]$ for all $x$ and $y$. This means that:

$$
s^{*}(x, y)=\left\{\begin{array}{c}
1 \text { iff } Y(x, y, 1)>Y(x, y, 0) \\
0 \text { otherwise }
\end{array}\right.
$$

Using the definition of $Y$ and rearranging yields:

$$
s^{*}(x, y)=\left\{\begin{array}{c}
1 \text { iff } v(x+f(y))-v(x)>v(y)-v(y(1-a)) \\
0 \text { otherwise }
\end{array}\right.
$$

Proof of Proposition \%: Under SA I and SA II, in equilibrium, more able leaders are matched with more able helpers.

Proof. By the implicit function theorem, write $z_{h}=z_{h}\left(z_{l}\right)$ the solution of Equation 1 and $z_{l}=z_{l}\left(z_{h}\right)$ the solution of Equation 2.

First, suppose that $z_{h}\left(z_{l}\right)$ and $z_{l}\left(z_{h}\right)$ are differentiable. Then, totally differentiating Equation 1 with respect to $z_{l}$ and Equation 2 with respect to $z_{h}$ and rearranging yields:

$$
\begin{aligned}
z_{h}^{\prime}\left(z_{l}\right) & =\frac{v^{\prime \prime}\left(z_{l}+f\left(z_{h}\right)\right) f^{\prime}\left(z_{h}\right)}{w_{h 1}^{\prime \prime}\left(z_{h}\right)-v^{\prime \prime}\left(z_{l}+f\left(z_{h}\right)\right)\left(f^{\prime}\left(z_{h}\right)\right)^{2}+v^{\prime}\left(z_{l}+f\left(z_{h}\right)\right) f^{\prime \prime}\left(z_{h}\right)+(1-a)^{2} v^{\prime \prime}\left(z_{h}(1-a)\right)} \\
z_{h}^{\prime}\left(z_{l}\right) & =\frac{v^{\prime \prime}\left(z_{l}+f\left(z_{h}\right)\right) f^{\prime}\left(z_{h}\right)}{w_{l 1}^{\prime \prime}\left(z_{l}\right)-v^{\prime \prime}\left(z_{l}+f\left(z_{h}\right)\right)}
\end{aligned}
$$


From the second order conditions in Equations 3 and 4, the denominators are strictly positive. Hence, $\left.z_{h}^{\prime}\left(z_{l}\right)\right)>0$ since $v^{\prime \prime}\left(z_{l}+f\left(z_{h}\left(z_{l}\right)\right)\right) f^{\prime}\left(z_{h}\left(z_{l}\right)\right)>0$ from SA I.3 and SA II.3 and $\left.z_{l}^{\prime}\left(z_{h}\right)\right)>0$ since $v^{\prime \prime}\left(z_{l}\left(z_{h}\right)+f\left(z_{h}\right)\right) f^{\prime}\left(z_{h}\right)>0$ from SA I.3 and SA II.3.

Suppose now that $z_{h}\left(z_{l}\right)$ and $z_{l}\left(z_{h}\right)$ are not differentiable. We can still prove that in equilibrium, more able leaders get more able helpers. Take two teams that arise in equilibrium say $\left(x_{i}, y_{i}\right), i=0,1$ where $x_{i}$ is the ability of the leader and $y_{i}$ the ability her helper. Without loss of generality, suppose that $x_{1}=x_{0}+h$ with $h>0$. From the second order conditions in Equations 3 and 4, we know that the wage profiles are steeper than the productivity profiles. Formally, and using the helper's problem for instance, we have that:

$$
\lim _{h \rightarrow 0} \frac{w_{l}^{\prime}\left(x_{0}+h\right)-w_{l}^{\prime}\left(x_{0}\right)}{h}=w_{l}^{\prime \prime}\left(x_{0}\right)>v^{\prime \prime}\left(x_{0}\right)=\lim _{h \rightarrow 0} \frac{v^{\prime}\left(x_{0}+h+f\left(y_{0}\right)\right)-v^{\prime}\left(x_{1}+f\left(y_{0}\right)\right)}{h}
$$

Using the first order condition in Equation 2 to replace $w_{l}^{\prime}($.$) obtains:$

$$
\begin{aligned}
\lim _{h \rightarrow 0} \frac{v^{\prime}\left(x_{0}+h+f\left(y_{1}\right)\right)-v^{\prime}\left(x_{0}+f\left(y_{0}\right)\right)}{h} & >\lim _{h \rightarrow 0} \frac{v^{\prime}\left(x_{0}+h+f\left(y_{0}\right)\right)-v^{\prime}\left(x_{1}+f\left(y_{0}\right)\right)}{h} \\
& \Leftrightarrow \\
y_{1} & >y_{0}
\end{aligned}
$$


It follows that in equilibrium, more able leaders are matched with more able helpers.

Proof of proposition 8: Under SA I and SA II, in equilibrium, no riders of ability lower than $z^{\left(l_{1}\right)}$ become leaders and no riders of ability higher than $z^{\left(l_{1}\right)}$ rider on their own.

Proof. Take any rider of ability $z \in Z$. The payoffs of this rider are $w_{l 1}(z)$ as a leader, $w_{h 1}(z)$ as a helper and $w_{0}(z) \equiv v(z)$ as an individual rider. A payoffs maximizing rider will therefore choose the role leading to $W(z)=$ $\max \left\{w_{l 1}(z), w_{h 1}(z), v(z)\right\}$. We are looking for the upper envelop $W(z)$ of the graph of payoffs $\left\{w_{l 1}(z), w_{h 1}(z), v(z)\right\}$ in $z$.

Without further restrictions, we already know from the first order conditions that leaders' payoffs function $w_{l 1}(z)$ is strictly steeper than that of individual riders $v(z)$, i.e. $w_{l 1}^{\prime}(z)=v^{\prime}\left(z+f\left(z_{h}\right)\right)>v^{\prime}(z)$ from SA II. Let $z^{\left(l_{1}\right)}$ be the ability of riders so that $w_{l 1}\left(z^{\left(l_{1}\right)}\right)=v\left(z^{\left(l_{1}\right)}\right)$. This implies that $w_{l 1}(z)<v(z) \leq W(z)$ for all $z<z^{\left(l_{1}\right)}$ and $W(z) \geq w_{l 1}(z)>v(z)$ for all $z>z^{\left(l_{1}\right)}$. It follows that in equilibrium, there are no leaders of ability lower than $z^{\left(l_{1}\right)}$ and no individual riders of ability higher than $z^{\left(l_{1}\right)}$. Stated otherwise, riders of ability lower than $z^{\left(l_{1}\right)}$ either become a helper or an individual 
rider, i.e. $w_{l 1}(z)<W(z)$ for all $z<z^{\left(l_{1}\right)}$, while riders of ability higher than $z^{\left(l_{1}\right)}$ either become a helper or a leader, i.e. $w_{0}(z)<W(z)$ for all $z>z^{\left(l_{1}\right)}$. - 


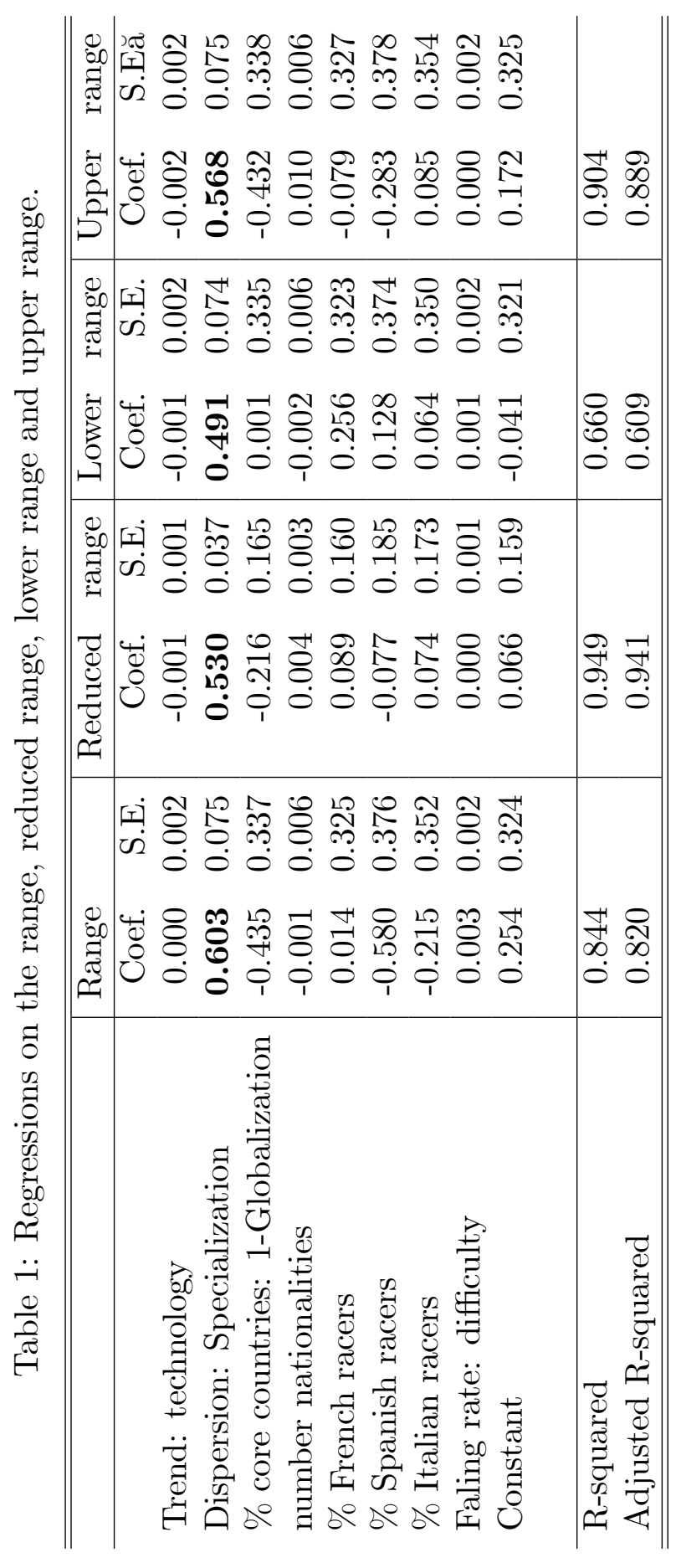




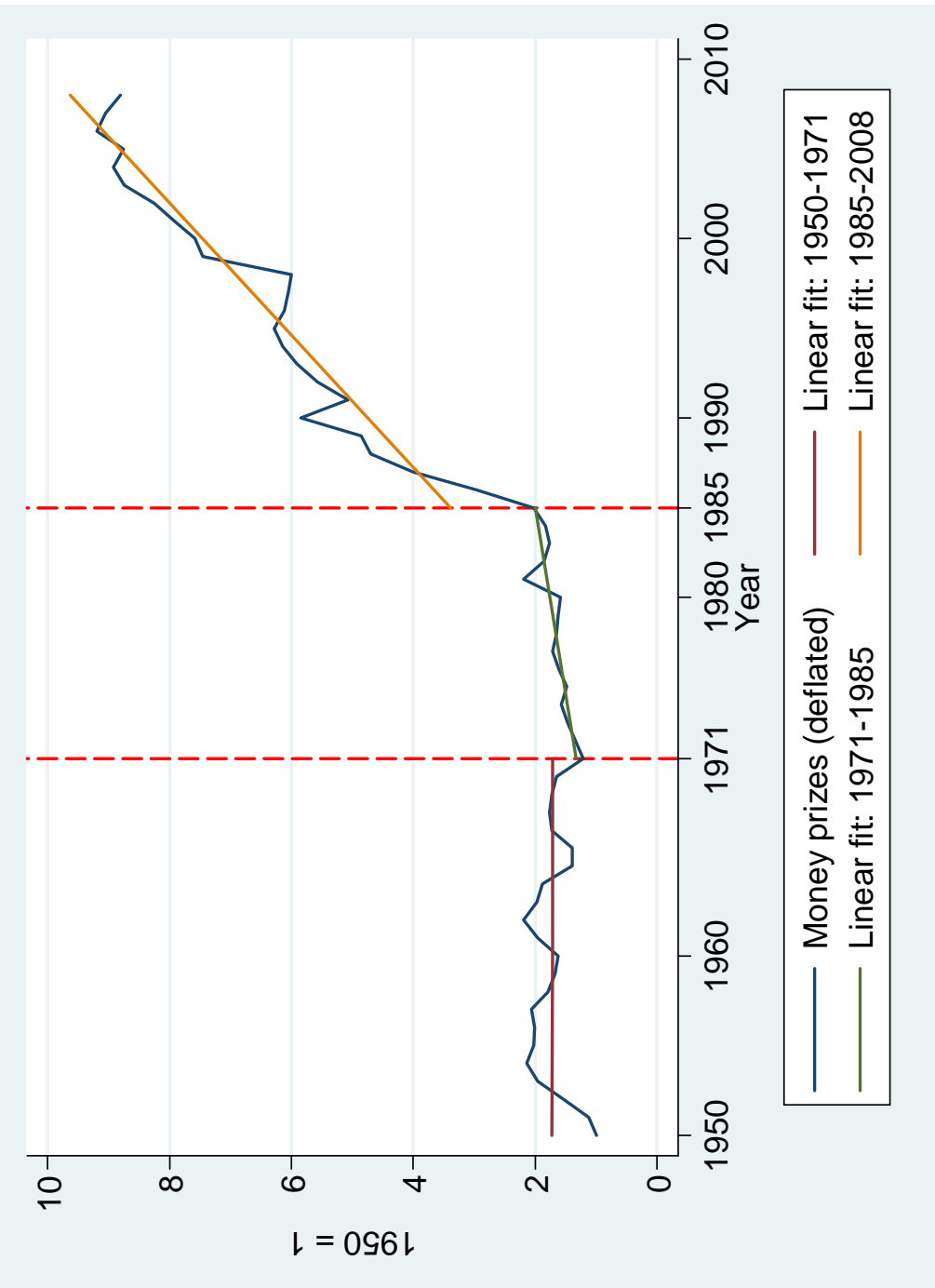

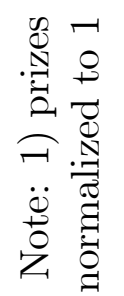

$\stackrel{\infty}{0}$

ㄱํㄹำ

ช

of

สี

สิก

空空

先

定

$\frac{9}{20}$

$\stackrel{\infty}{9}$

키을

엄

ق

들

苛

$\rightarrow 2$

泀 总

. సै

전

용

낭 .

苛

되당

$\ddot{-}$ हี

○。

50

社 气 


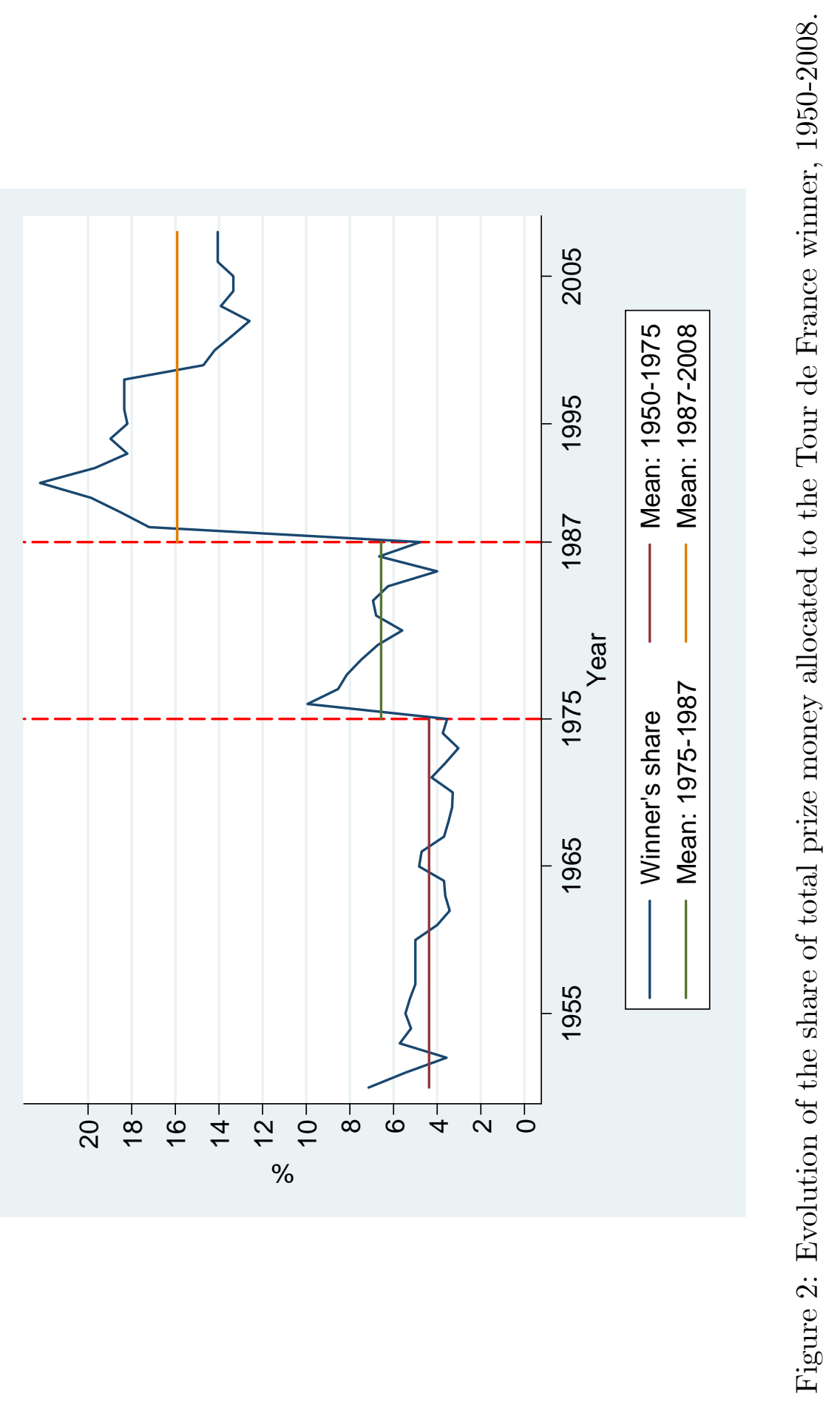



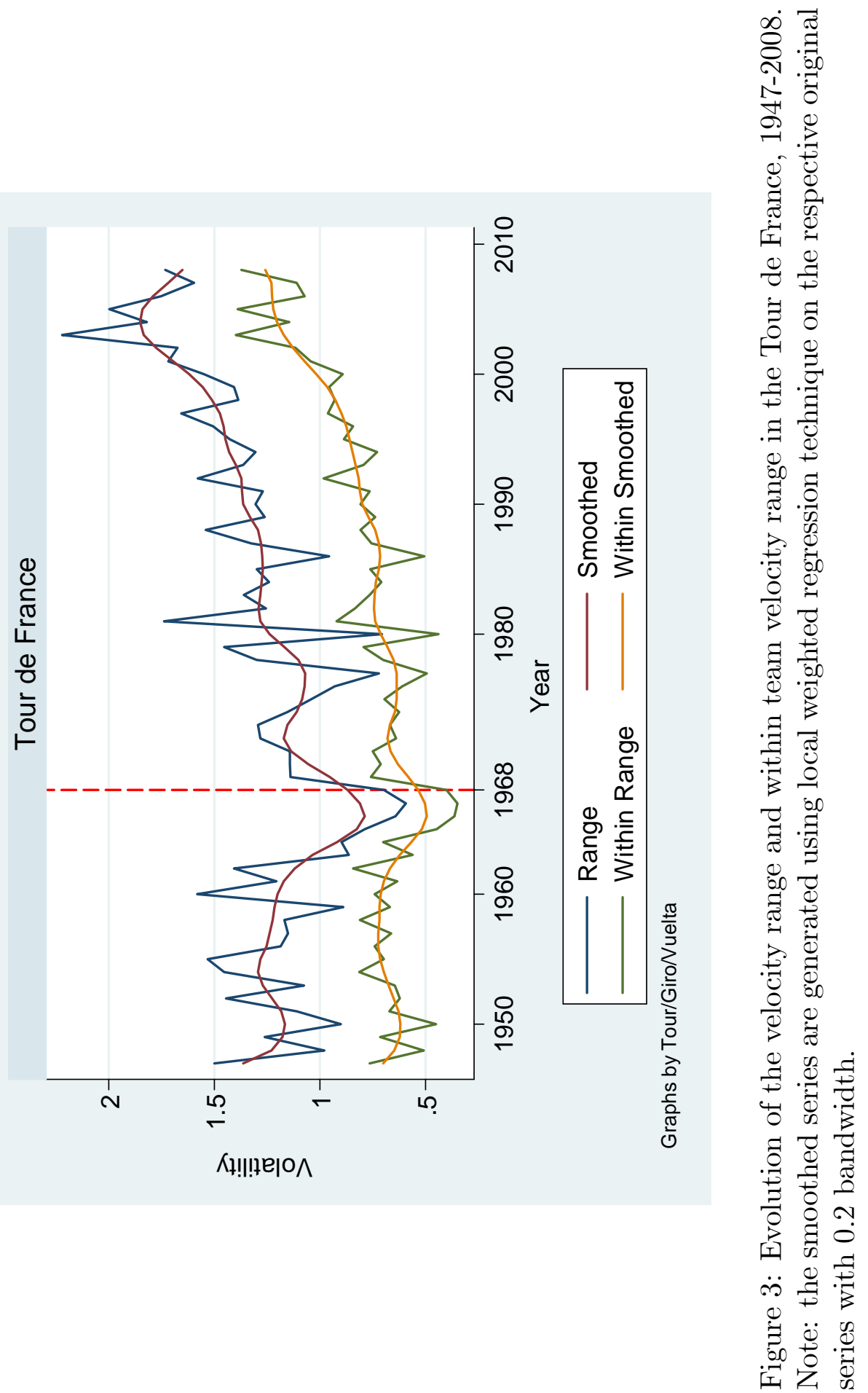


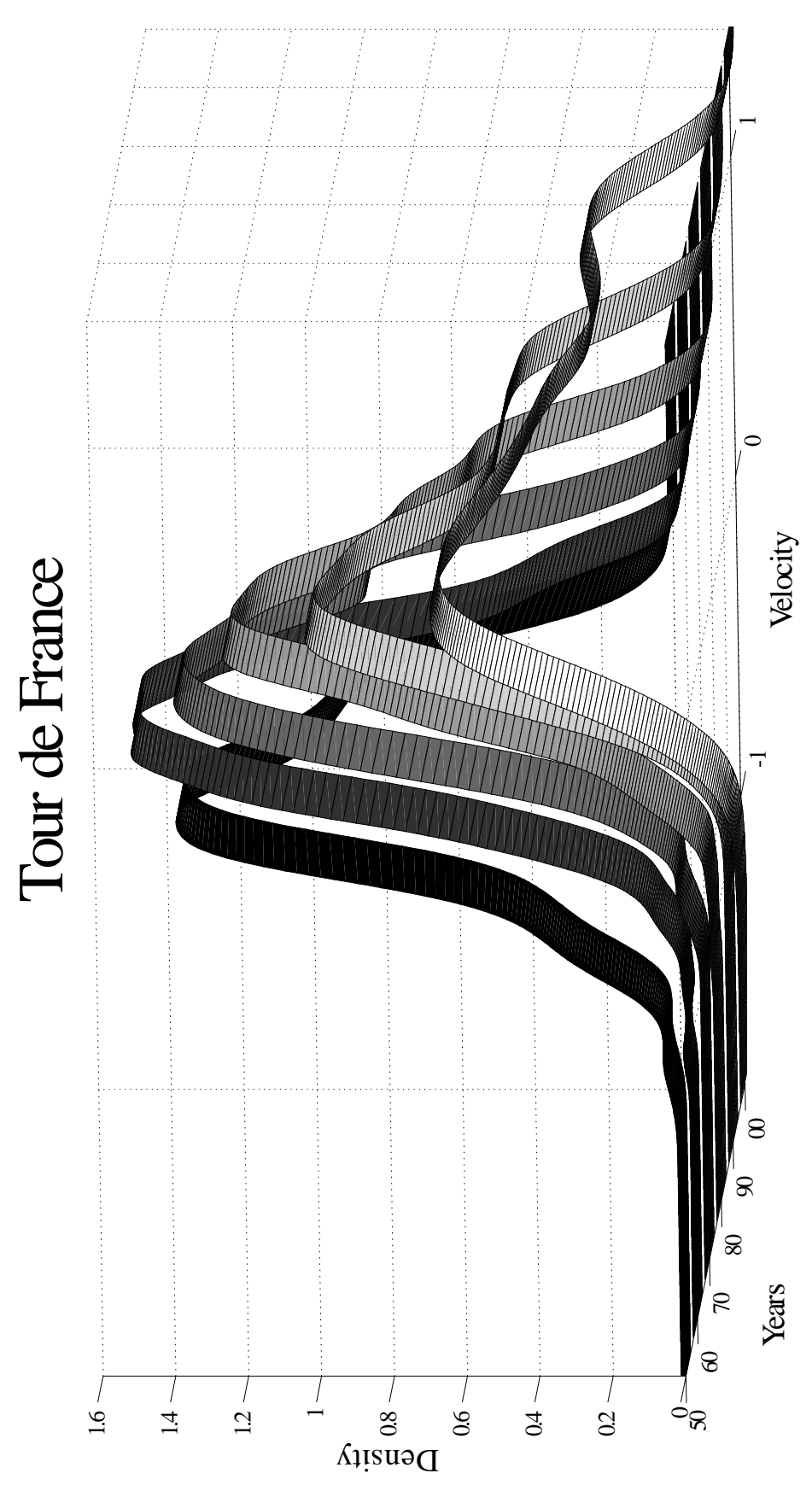

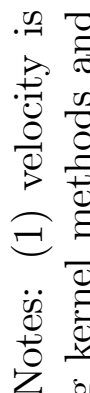

○.

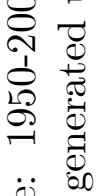

ن.

婇 卷

웡

긍 웡

엄

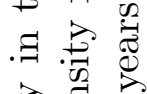

.

$\stackrel{0}{0}$

Чै

莺

责

पै की

总完急

ते 200

田哥

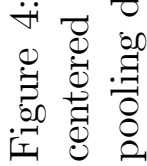



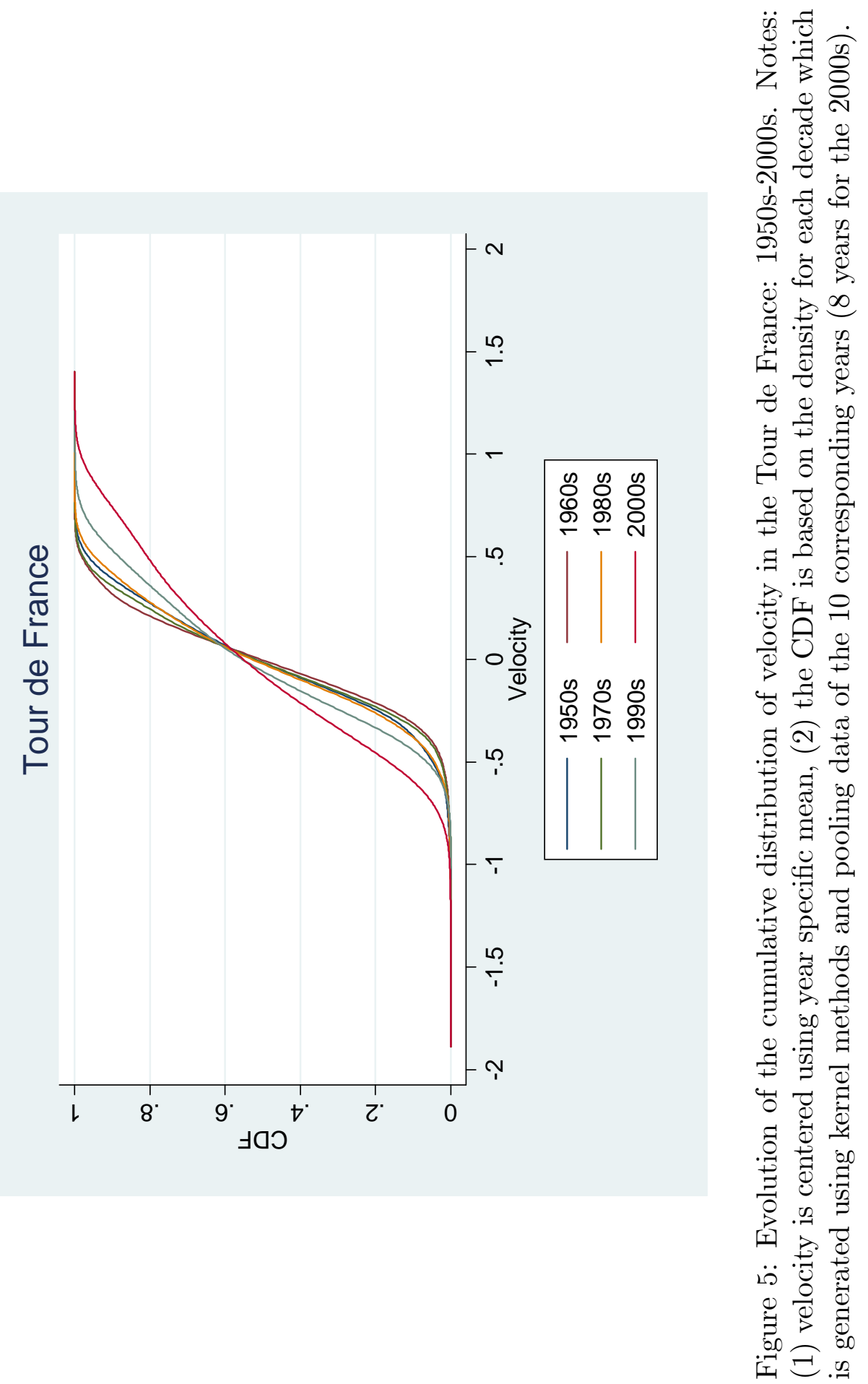


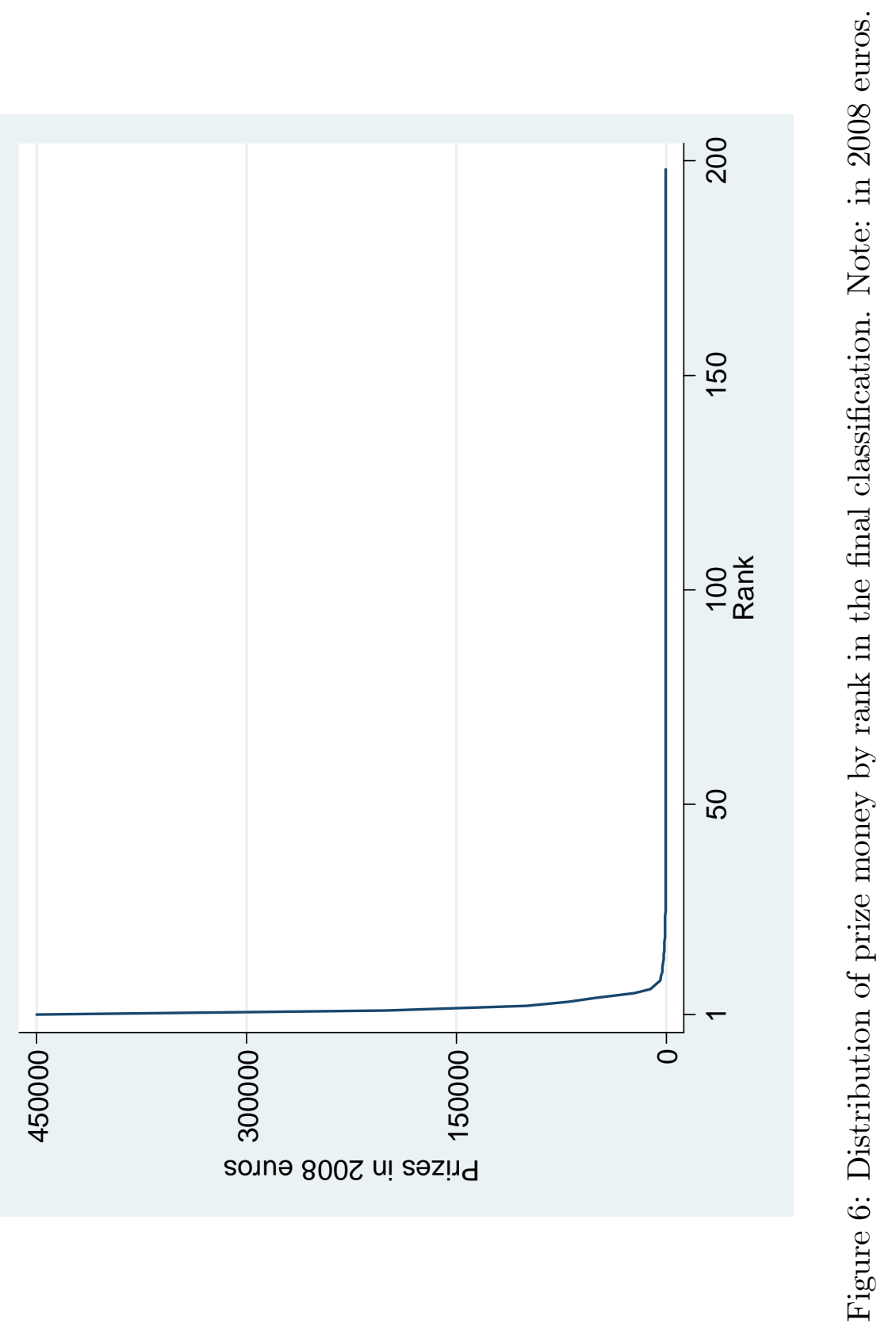

